Regular Article

\title{
RNA-mediated, green synthesis of palladium nanodendrites for catalytic reduction of nitroarenes
}

\author{
Fuat Topuz $^{\mathrm{a}}$, Tamer Uyar ${ }^{\mathrm{a}, \mathrm{b}}$ \\ a Institute of Materials Science \& Nanotechnology, Bilkent University, Ankara, 06800, Turkey \\ ${ }^{\mathrm{b}}$ Department of Fiber Science \& Apparel Design, College of Human Ecology, Cornell University, Ithaca, NY, 14853, USA
}

G R A P H I C A L A B S T R A C T

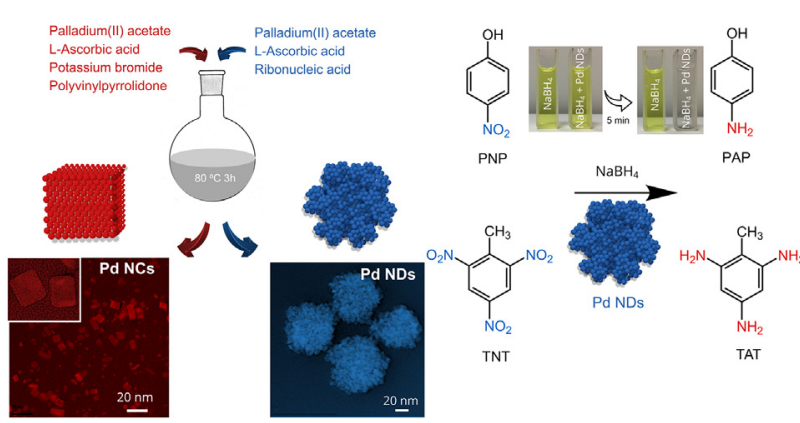

\section{A R T I C L E I N F O}

\section{Article history:}

Received 11 December 2018

Accepted 25 February 2019

Available online 26 February 2019

\section{Keywords}

Pd nanoparticles

Nanodendrites

Ribonucleic acid (RNA)

Flower-like nanoparticles

Catalytic nanoparticles

2,4,6-Trinitrotoluene (TNT)

p-Nitrophenol (PNP)

\begin{abstract}
A B S T R A C T
Palladium (Pd)-catalyzed reactions mostly show structure sensitivity: i.e., the selectivity and activity of the reactions are highly dependent on the arrangement of Pd atoms. In this regard, branched Pd nanoparticles show enhanced catalytic performance owing to the presence of low coordinated Pd atoms. In this paper, a novel solution-phase synthesis of flower-like Pd nanodendrites using ribonucleic acid (RNA) as a capping agent and ascorbic acid as a reducing agent was described. On the other hand, the co-use of polyvinylpyrrolidone (PVP) and potassium bromide $(\mathrm{KBr})$ instead of RNA at the same synthesis conditions led to cuboid nanoparticles, while the sole use of ascorbic acid resulted in faceted nanoparticles. The formation of nanodendritic morphology was attributed to the RNA-assisted growth through particle attachment. This scenario was supported by TEM analysis that demonstrated the aggregation of small particles to form larger nanoparticles at the onset of the reaction. The shape and size of the nanoparticles could be readily tuned by the RNA content used. XPS confirmed the formation of metallic Pd nanoparticles. The

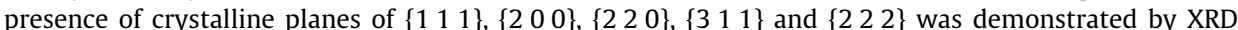
and SAED analyses. The Pd nanodendrites were used for the reduction of $p$-nitrophenol (PNP) and 2,4,6-trinitrotoluene (TNT), and reduction rate constants $\left(k\right.$ ) were calculated as $1.078 \mathrm{~min}^{-1}$ (normalized rate constant, $\left.k_{\text {nor }}=59.66 \mathrm{mmol}^{-1} \mathrm{~s}^{-1}\right)$ for PNP and $0.3181 \mathrm{~min}^{-1}\left(k_{\text {nor }}=17.6 \mathrm{mmol}^{-1} \mathrm{~s}^{-1}\right)$ for TNT with the corresponding turnover frequencies (TOFs) as 16.06 and $40.80 \mathrm{~h}^{-1}$, respectively.
\end{abstract}

(c) 2019 Elsevier Inc. All rights reserved.
E-mail addresses: fuat.topuz@rwth-aachen.de (F. Topuz), tu46@cornell.edu (T. Uyar)

\section{Introduction}

Noble metal nanoparticles have attracted tremendous interest in a wide spectrum of applications, including photonics [1], electronics [2], sensing [3], biomedicine [4], and imaging [5]. They have 
been also exploited as heterogeneous nanocatalysts with facile catalyst recovery and recyclability, along with low catalyst loading. In this regard, sole palladium (Pd) nanoparticles or together with other noble metals (e.g., Pt [6], Au [7], or Ag [8]) in different shapes and sizes have been reported for their efficient catalytic performance in carbon-carbon cross-coupling e.g., Suzuki, Heck and Stille coupling reactions [9-11], as electrocatalysts in fuel cells [12], oxygen reduction reactions [13], oxidation of small molecules (e.g., formic acid [14,15], ethanol [15,16], and methanol [15,17]) and hydrogenation reactions [18-20]. Since chemical reactions take place on the particle surface, enhancing surface area with a highly branched morphology directly boosts the catalytic performance of the nanoparticles owing to the presence of low coordinated atoms, mostly located in defects, such as edges and kinks [21,22]. Most Pd nanoparticles have been synthesized through chemical and electrochemical routes by the nucleation of Pd atoms toward seeds and later nanoparticles at room temperature [23,24]. However, the nucleation can be accelerated with a temperature rise, which occasionally generates nanoparticles with concave surfaces [25].

Since Pd nanoparticles serve as a reservoir for atomic Pd, higher interface, particularly the presence of edge and corner atoms rises the catalytic activity of the nanoparticles [26]. However, most Pd nanoparticles have low surface energy because their surface is mainly covered by low index $\left\{\begin{array}{lll}1 & 0 & 0\end{array}\right\}$ and $\left\{\begin{array}{lll}1 & 1 & 0\end{array}\right\}$ planes, and such nanoparticles offer less catalytic activity than flower-like nanodendrites. In this regard, a facile and green synthesis of highly branched Pd nanoparticles, such as nanodendrites, is always desired owing to their high degree of structural anisotropy, along with highly active facets, which significantly enhance the catalytic performance of nanoparticles than the particles having low index facets. To date, flower-like Pd nanoparticles have been synthesized using various routes and precursors. In one example, flower-like Pd nanoparticles were synthesized using strongly hydrophobic surfactants, e.g., didodecyldimethylammonium bromide and dimethylenebis(tetradecyldimethylammonium bromide), and the formation of the flower-like morphology was credited to the selfaggregation of Pd seeds [27]. Mohanty et al. described a common strategy for the synthesis of nanodendrites from $\mathrm{Pt}, \mathrm{Pd}$ and $\mathrm{Au}$ using an amino acid based surfactant, sodium N-(4-n-dodecyloxy benzoyl)-L-isoleucinate (SDLIL) and observed that the $\mathrm{pH}$ dependent self-assembly is critical for particle growth [9]. Recently, Ye et al. reported the synthesis of chestnut-bur-like Pd nanoparticles using cetylpyridinium chloride (CPC) as a capping agent in aqueous solutions and implemented the nanoparticles for ethanol oxidation [28]. Shin et al. reported flower-like Pd nanoparticles decorated with graphene electrodes for ultrasensitive and flexible hydrogen gas sensing, where the particles were synthesized through electrochemical methods using $0.1 \mathrm{M} \mathrm{PdCl}_{2}$ into $100 \mathrm{mM} \mathrm{H}_{2} \mathrm{SO}_{4}$ [29]. Liu et al. reported flower-like Pd nanoparticles, which were produced by a seed-mediated method at room temperature using cetyltrimethylammonium chloride (CTAC) and ice-cold $\mathrm{NaBH}_{4}$ solution [30]. Recently, Wang et al. reported the controlled synthesis of hierarchical Pd nanodendrites using Pd $(\mathrm{OAc})_{2}$ as a Pd source, PVP as a stabilizer, $\mathrm{CO}$ as a reducing agent in the presence of sodium acetate and oleylamide at $100^{\circ} \mathrm{C}$ for $3 \mathrm{~h}$ [31]. The formation of Pd seeds was controlled by CO and acetate anions while oleylamide promoted the growth of hierarchical branches. Likewise, oleylamine was used to the controlled nucleation of Pd nanoparticles and their assembly into dendrites [32]. The particle synthesis was performed using palladium acetylacetonate $\left(\mathrm{Pd}(\mathrm{acac})_{2}\right)$ as a Pd precursor, and oleylamine served as both capping agent and solvent in an argon atmosphere from room temperature to $130{ }^{\circ} \mathrm{C}$ at a rate of about $20^{\circ} \mathrm{C} \mathrm{min}{ }^{-1}$. The formation of Pd nanodendrites via an aggregation-based growth mechanism was revealed by TEM analysis.

In this study, flower-like Pd nanodendrites were synthesized through RNA-mediated growth of Pd atoms in water using L-ascorbic acid as a reducing agent (Fig. 1). RNA-mediated hexagonal Pd nanoparticles were previously reported by Eaton and coworkers [33]. However, to the best of authors' knowledge there is no report on the RNA-mediated synthesis of Pd nanodendrites. Pd nanoparticles were also synthesized using only ascorbic acid or in the presence of ascorbic acid/KBr/PVP under same conditions. The particles were characterized in terms of shape and structure by

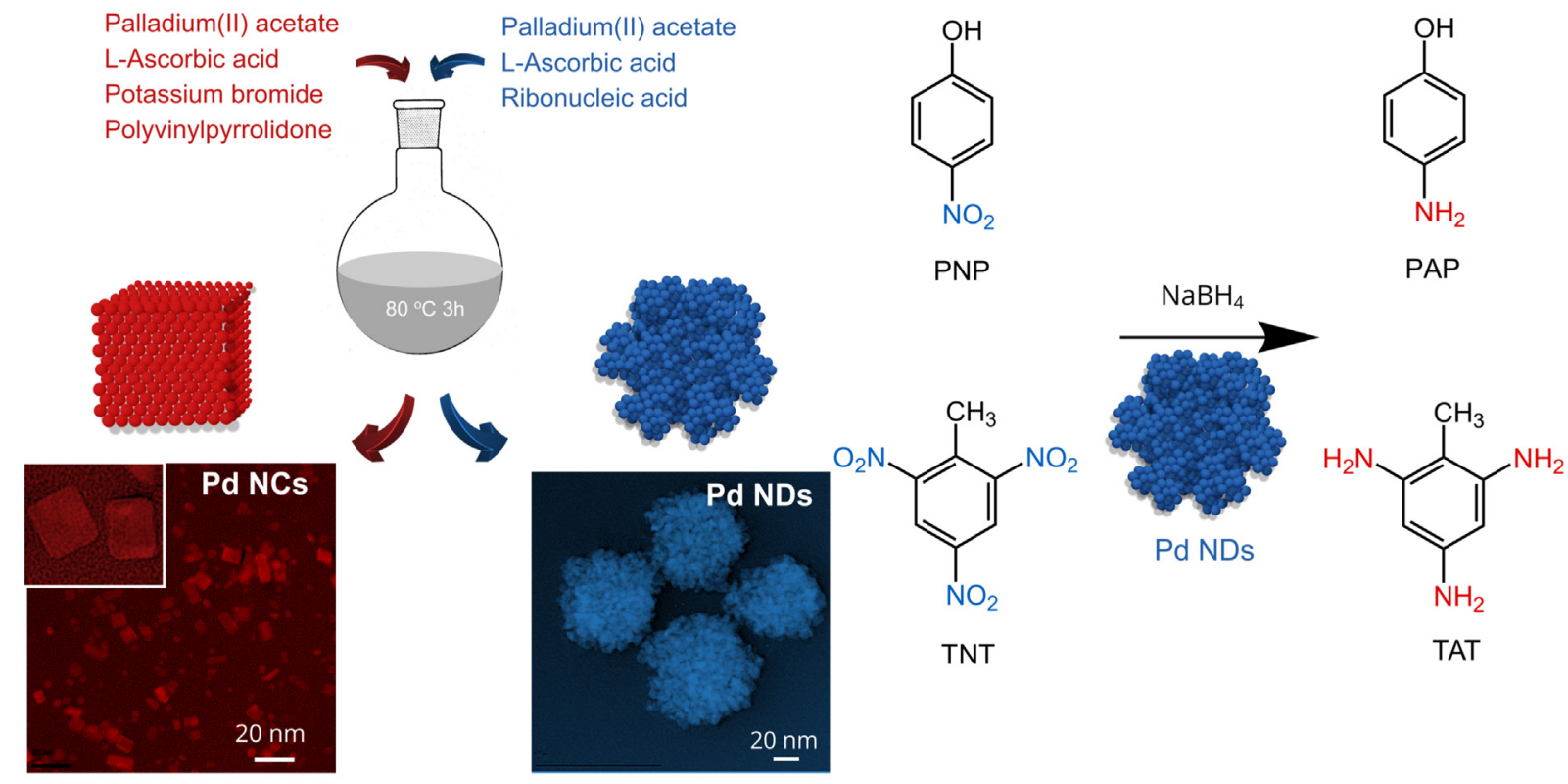

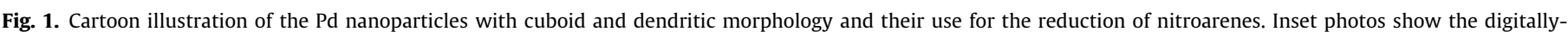

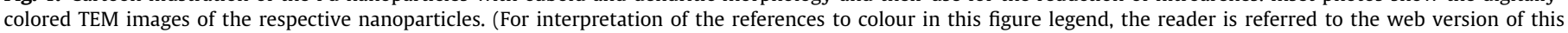
article.) 
TEM, STEM and SAED analysis, oxidation state of Pd by XPS, and crystallographic planes by XRD. The formation of Pd nanoparticles was discussed in terms of underlying mechanism in guiding the particle morphology. Finally, the nanoparticles were used for the reduction of $p$-nitrophenol (PNP) and 2,4,6-trinitrotoluene (TNT) to $p$-aminophenol (PAP) and 2,4,6-triaminotoluene (TAT), respectively.

\section{Experimental section}

\subsection{Materials}

Palladium(II) acetate trimer (( $\left.\left.\mathrm{Pd}(\mathrm{OAc})_{2}\right)_{3}, \mathrm{Pd} ; 45.9-48.4 \%\right)$ was purchased from Alfa Aesar (Germany). Polyvinylpyrrolidone (PVP, $\mathrm{SP}^{2}$ ) with an average molecular weight of $M_{\mathrm{w}}=360 \mathrm{~kg} / \mathrm{mol}$, potassium bromide (KBr, 99\%, Sigma Aldrich), L-ascorbic acid (AA, Sigma Aldrich), ribonucleic acid sodium salt (RNA from Yeast, TCI Chemicals), $p$-nitrophenol (PNP, 99\%, Alfa Aesar), ethanol (EtOH, Sigma Aldrich), and sodium borohydride $\left(\mathrm{NaBH}_{4}\right.$, fine granular, Merck) were received.

\subsection{Synthesis of Pd nanoparticles}

Pd nanoparticles were synthesized at $80^{\circ} \mathrm{C}$ using different capping agents. For the synthesis of cuboid Pd nanoparticles, the mixture of PVP (210 mg), $\mathrm{KBr}$ (150 mg) and AA (120 mg) was dissolved in $16 \mathrm{~mL}$ water and stirred for $\sim 30 \mathrm{~min}$. Afterwards, an aqueous solution of $\mathrm{Pd}(\mathrm{OAc})_{2}$ was added dropwise. The reaction was conducted at $80^{\circ} \mathrm{C}$ for $3 \mathrm{~h}$ under continuous stirring. The nanoparticles were separated by centrifugation at $13,000 \mathrm{rpm}$ for $20 \mathrm{~min}$, and organic reactants were removed by washing with water and ethanol. On the other hand, flower-like Pd nanodendrites were synthesized at the same conditions using RNA as the capping agent at various concentrations and ascorbic acid as a reducing agent. RNA (at various concentrations) was dissolved in water $(16 \mathrm{~mL})$ and heated to $80^{\circ} \mathrm{C}$ and thereafter, AA (120 mg) was added and the solution stirred until both additives were completely dissolved. Afterwards, an aqueous solution of $\mathrm{Pd}(\mathrm{OAc})_{2}$ was added dropwise and stirred for $\sim 30 \mathrm{~min}$. The reaction was conducted at $80^{\circ} \mathrm{C}$ for $3 \mathrm{~h}$ under continuous stirring. The nanoparticles were separated by centrifugation at $13,000 \mathrm{rpm}$ for $20 \mathrm{~min}$, and organic reactants were removed by washing with water and ethanol. Pd nanoparticles were also produced using only ascorbic acid.

\subsection{Characterization methods}

Transmission electron microscopy (TEM) was performed using a Tecnai G2F30 (FEI) apparatus. The aqueous solutions of the nanoparticles were dropped and dried on carbon-coated copper grids. TEM was operated with an accelerating voltage of $300 \mathrm{kV}$. Scanning transmission electron microscopy (STEM) mode was used to characterize the nanoparticles. X-Ray photoelectron spectra of
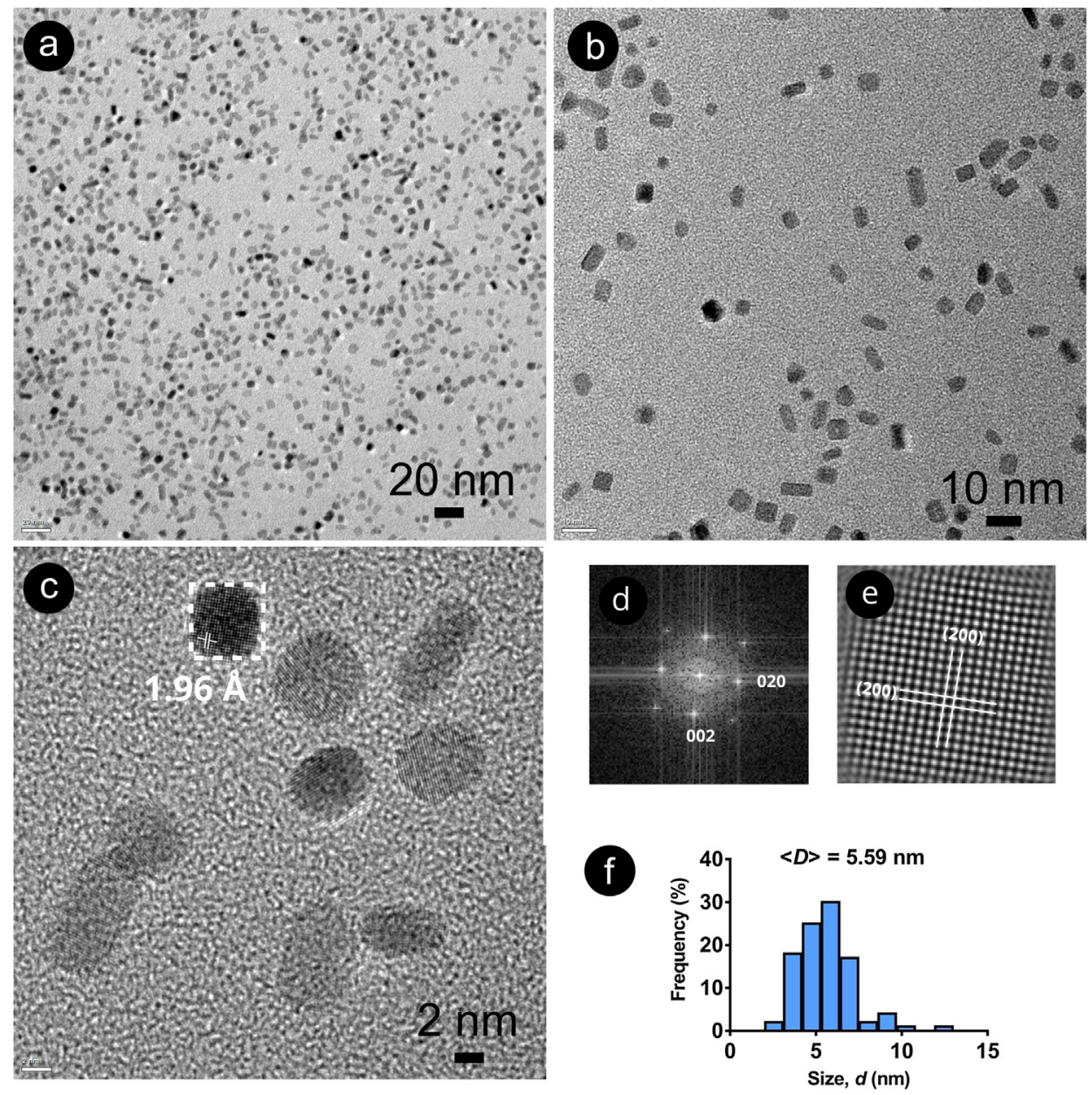

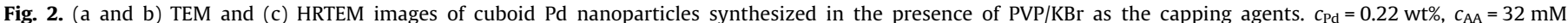

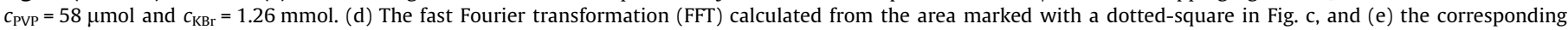
inverse-FFT pattern. (f) The size-distribution plot of the Pd nanoparticles. 
the samples were recorded using an X-ray photoelectron spectrometer (Thermo Fisher Scientific, U.K.). Al K- $\alpha$ X-ray monochromator $(0.1 \mathrm{eV}$ step size, $12 \mathrm{kV}, 2.5 \mathrm{~mA}$, spot size $400 \mu \mathrm{m})$ was exploited as an X-ray source at an electron take-off angle of $90^{\circ}$. XPS spectra of Pd 3d orbital were measured 30 times with $50 \mathrm{~ms}$ dwell time (pass energy $30 \mathrm{eV}$ ). X-Ray diffraction experiments were performed using a PANalytical X'Pert Pro MPD, which was powered by a Philips PW3040/60 X-ray generator fitted with an $\mathrm{X}$ 'Celerator detector. X-Rays were generated from a $\mathrm{Cu}$ anode that was supplied with $40 \mathrm{kV}$ and current of $40 \mathrm{~mA}$. The data were collected in the $2 \theta$ range of $30-90^{\circ}$ using the scanning $X^{\prime}$ Celerator detector system. All scans were carried out in continuous mode, and the data were analyzed using X'Pert Highscore Plus software (version 2.0).

\subsection{Catalytic activity tests}

Catalytic tests were carried out in a standard quartz cuvette with an optical length of $1 \mathrm{~cm}$. The Pd nanoparticles were homogenously dispersed and freshly used for the measurements.

p-Nitrophenol (PNP) reduction: An aqueous solution $(2.9 \mathrm{~mL}$, $0.055 \mathrm{mM}$ ) of PNP was transferred into a cuvette. Afterwards, $150 \mu \mathrm{L}$ of $0.3 \mathrm{M} \mathrm{NaBH}_{4}$ was added. After the addition from the dispersion of Pd nanoparticles at various volumes, UV-Vis spectra were collected on a Cary-UV 100 spectrophotometer every 30 or 60 s depending on the reaction rate within the wavelength range of $250-500 \mathrm{~nm}$. The intensity of the absorption peak at $400 \mathrm{~nm}$ was used for the calculation of the PNP conversion to p-aminophenol (PAP). The measurements were performed at room temperature $\left(25^{\circ} \mathrm{C}\right)$.

2,4,6-Trinitrotoluene (TNT) reduction: An aqueous solution $(0.4 \mathrm{~mL}, 1.01 \mathrm{mM})$ of TNT was transferred into a cuvette. Afterwards, $200 \mu \mathrm{L}$ of $0.3 \mathrm{M} \mathrm{NaBH}_{4}$ and $3 \mathrm{~mL}$ water were added. After the addition from the dispersion of Pd nanoparticles at various volumes, UV-Vis spectra were collected every 30 or 60 s depending on the reaction rate in the wavelength range of $250-600 \mathrm{~nm}$. The intensity of the absorption peak at $\sim 420 \mathrm{~nm}$ was used for the conversion of TNT to triaminotoluene (TAT). The measurements were performed at room temperature $\left(25^{\circ} \mathrm{C}\right)$.

\section{Results \& discussion}

Pd nanoparticles were synthesized through a facile, one-pot method in the presence of $\mathrm{KBr} / \mathrm{PVP}$ or RNA at $80^{\circ} \mathrm{C}$. The use of $\mathrm{KBr} / \mathrm{PVP}$ as the capping agents first led to the formation of small nanoparticles through the nucleation of Pd atoms, followed by the growth of these particles to larger ones via a seed-growth mechanism. Fig. 2(a and b) shows the TEM images of the Pd nanoparticles, which were synthesized in the presence of $\mathrm{KBr} / \mathrm{PVP}$ and reducing agent, L-ascorbic acid. The particle morphology was not uniform and displayed the presence of cuboid and cubic nanoparticles. The HRTEM image demonstrates that the Pd nanoparticles are crystalline as shown by well-defined fringe patterns (Fig. 2c). In the HRTEM image, the crystal fringes can be indexed as the $\left\{\begin{array}{lll}2 & 0 & 0\end{array}\right\}$ planes. Fig. 2d displays the corresponding
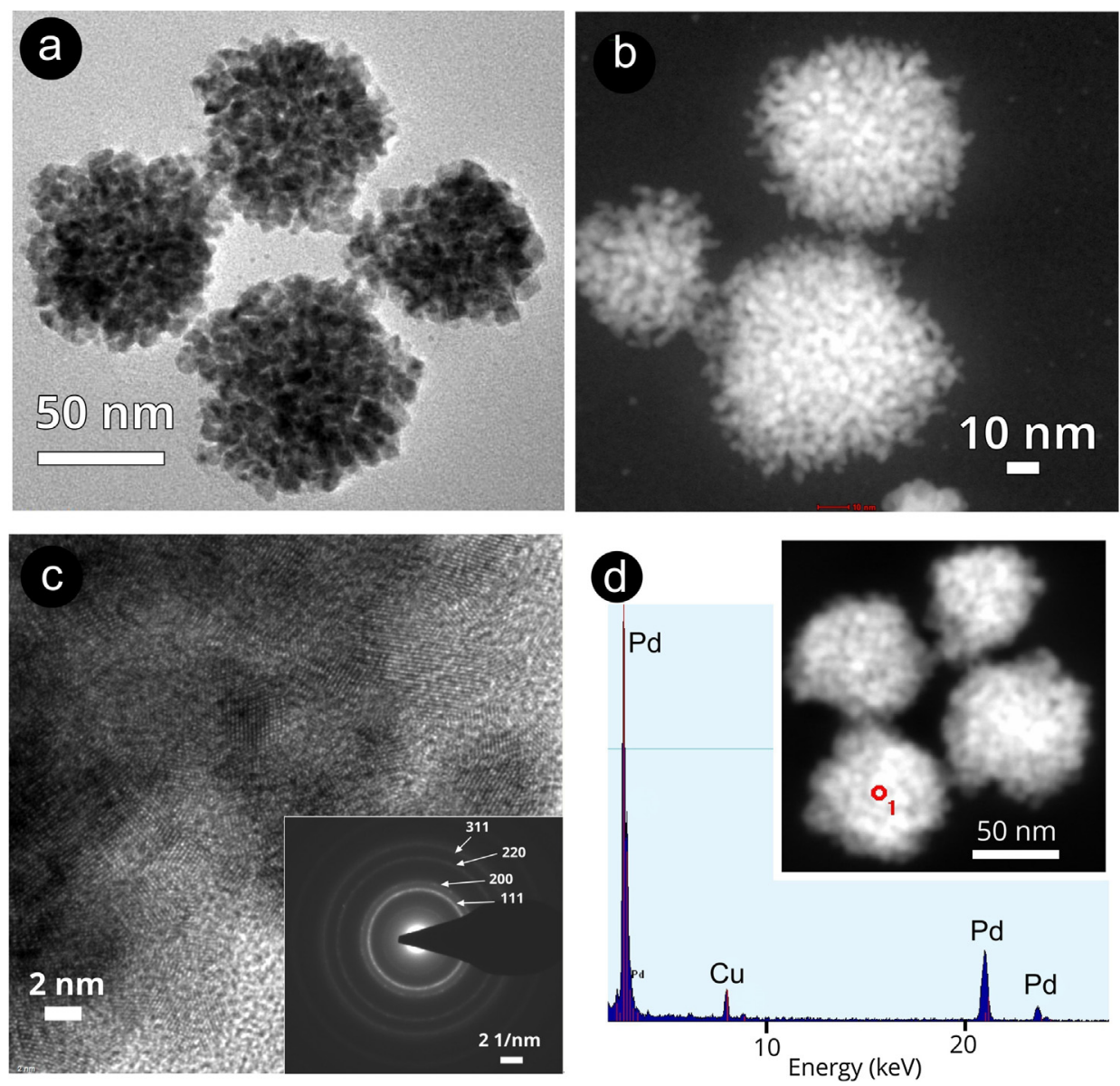

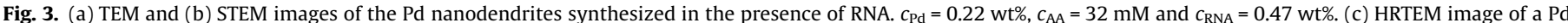

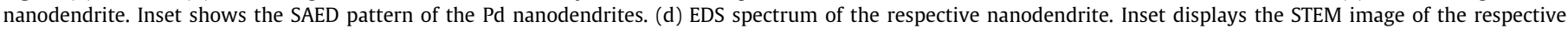
nanodendrites. 
fast-Fourier transform (FFT) image of the Pd nanoparticle. The FFT pattern shows $\left\{\begin{array}{lll}2 & 0 & 0\end{array}\right\}$ plane with a corresponding lattice space of $1.96 \AA$. Fig. 2e shows the inverse Fast-Fourier Transform (FFT) image reconstructed from the mask-applied FFT image of the area selected in Fig. 2c. The plane $\{200\}$ is clearly observed and ascribed to a face centered cubic (fcc) Pd. The mean size of the nanoparticles was measured as $5.60 \mathrm{~nm}$ (Fig. 2f).
Unlike cuboid nanoparticles obtained with $\mathrm{PVP} / \mathrm{KBr}$, the use of RNA as the capping agent led to flower-like Pd nanodendrites. Fig. 3 shows the morphology of Pd nanoparticles synthesized using $0.47 \mathrm{wt} \%$ RNA as the capping agent. TEM images of the nanoparticles revealed the formation of a three-dimensional nanodendrite morphology whose core was denser than the corona because of a high number of branches. Their highly branched structure was also
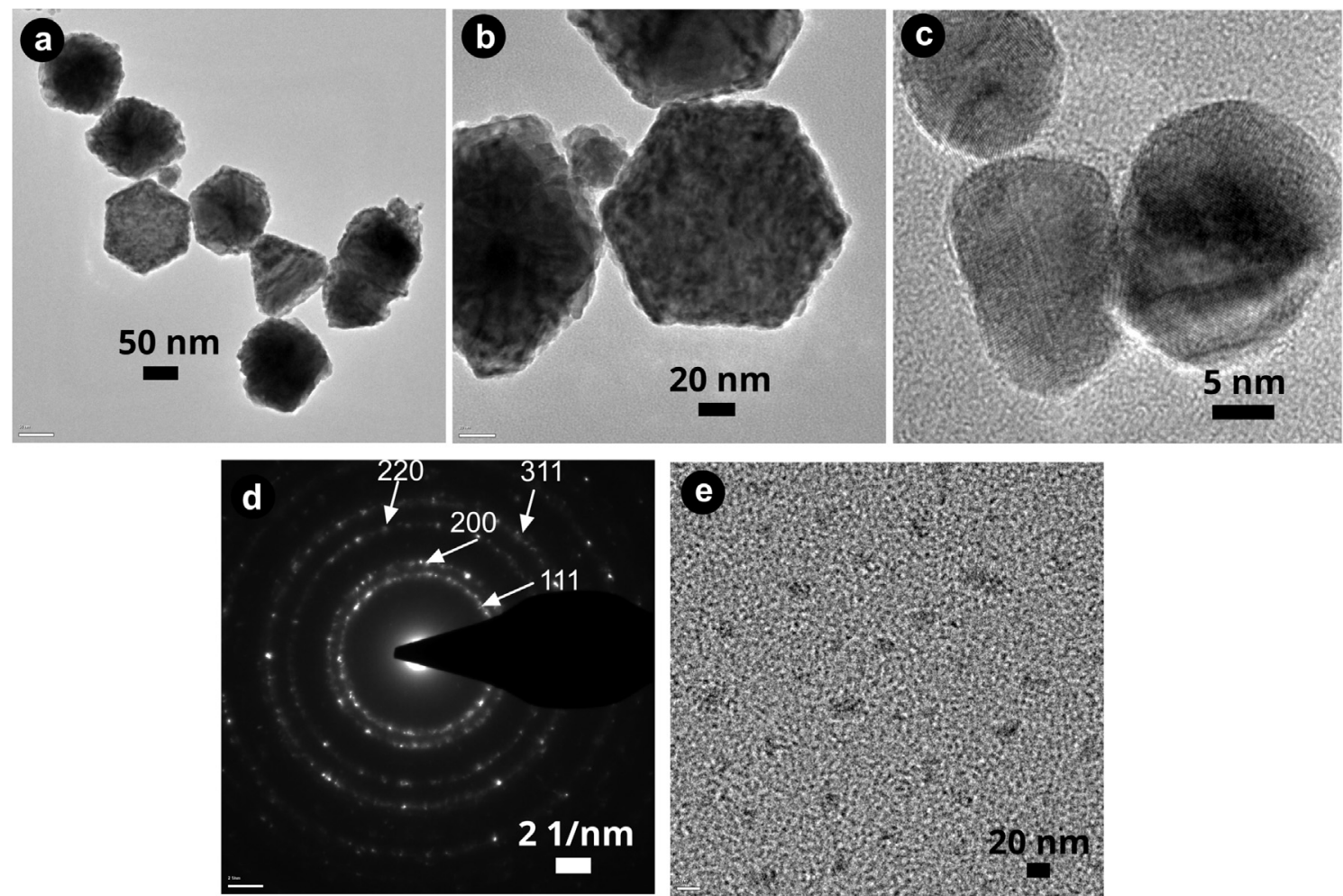

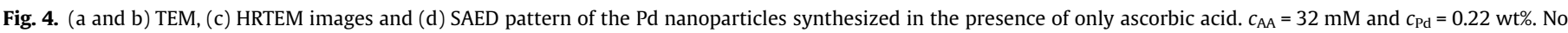

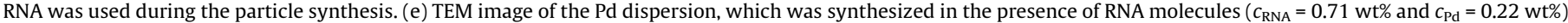
and absence of ascorbic acid.
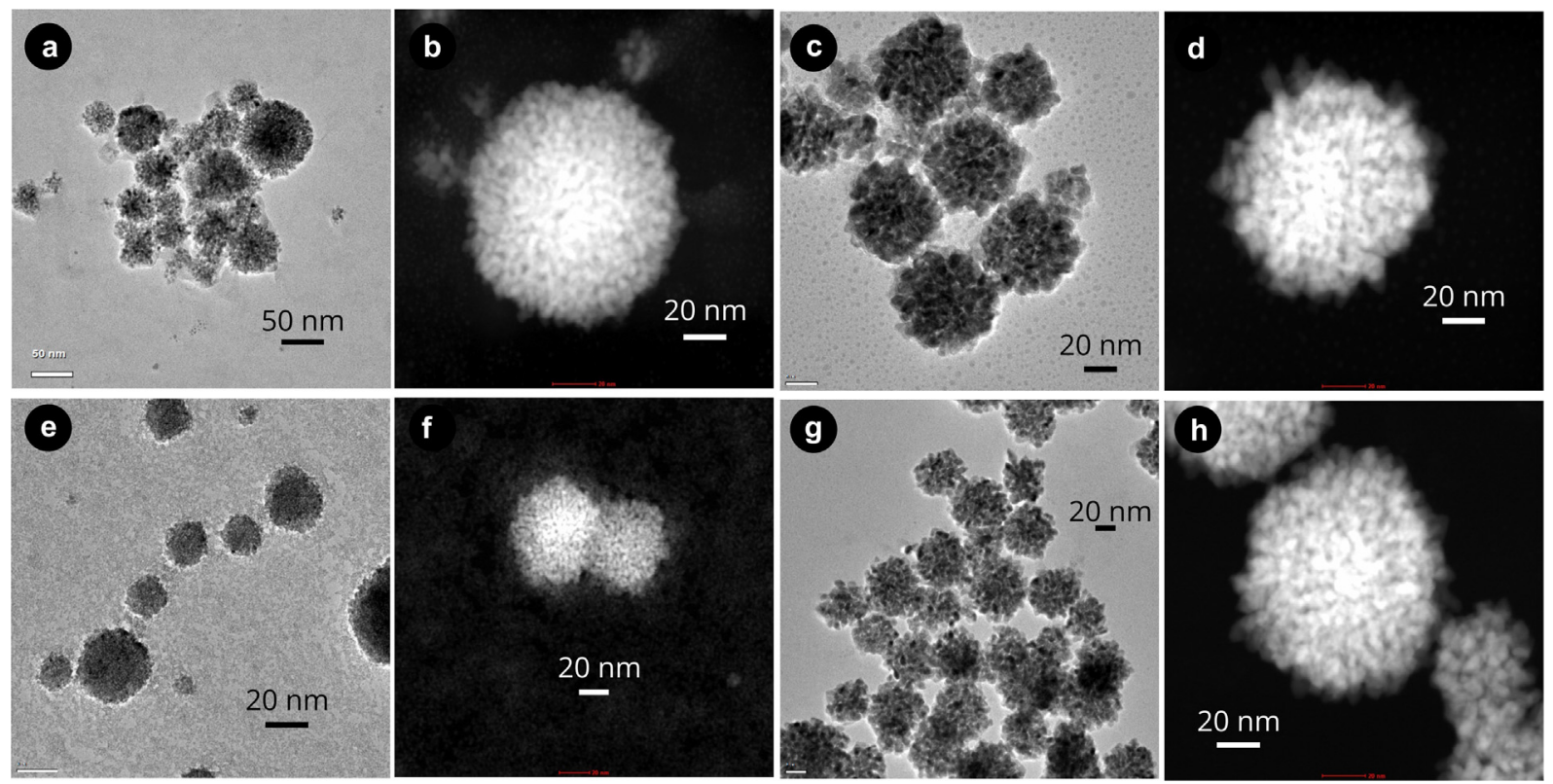

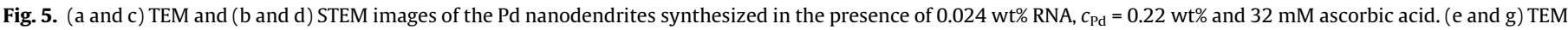
and (f and h) STEM images of the Pd nanodendrites synthesized in the presence of $0.048 \mathrm{wt} \%$ RNA and $32 \mathrm{mM}$ ascorbic acid. $c_{\mathrm{Pd}}=0.22 \mathrm{wt} \%$. 
confirmed by the STEM image with a highly dense core (Fig. 3b) The particles were obtained in the shape of nanoflowers in the size range between 50 and $70 \mathrm{~nm}$. HRTEM image displayed the presence of different crystalline fringes, suggesting their polycrystalline nature (Fig. 3c). The selected area electron diffraction (SAED) pattern revealed the presence of various planes, e.g., $\left\{\begin{array}{lll}1 & 1 & 1\end{array}\right\},\left\{\begin{array}{lll}2 & 0 & 0\end{array}\right\},\left\{\begin{array}{lll}2 & 2 & 0\end{array}\right\}$ and $\left\{\begin{array}{lll}3 & 1 & 1\end{array}\right\}$ of fcc Pd (Fig. 3c, inset). The EDS analysis of the respective particles revealed the peaks related to the Pd atom, demonstrating the formation of Pd nanoparticles (Fig. 3d). As the capping agents can affect the performance of Pd nanoparticles by restricting the accessibility of active sites, the removal of RNA from the nanoparticle surface can enhance their performance in catalytic applications. On the other hand, the use of RNA together with PVP led to unshaped small nanoparticles, suggesting that the incorporated PVP disturbed the nanodendritic morphology (Fig. S1). Similar nanodendritic morphology was reported by Yamauchi and co-workers for Pt using Brij58 as the capping agent [34].

Pd nanoparticles were also prepared in the absence of RNA using only ascorbic acid. Interestingly, the nanoparticles with faceted morphology were formed, including the forms of trigon, pentagon, and hexagon whose sizes ranged between 100 and $150 \mathrm{~nm}$ (Fig. 4(a-c)). Unlike the Pd nanoparticles synthesized in the presence of RNA, no aggregation or small particles was observed, suggesting their formation via a seed growth mechanism. The SAED pattern of the respective particles revealed highly
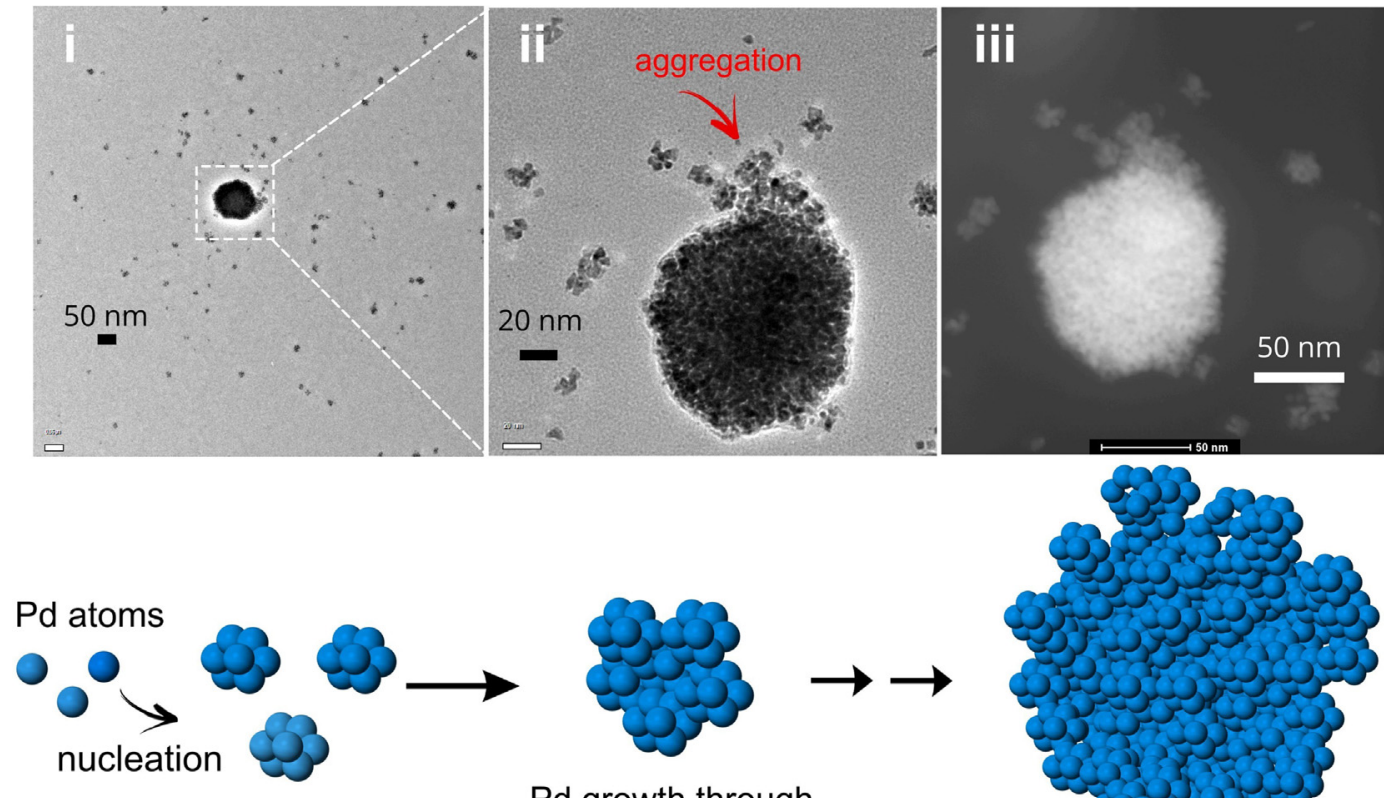

Pd seeds

Pd growth through particle attachment

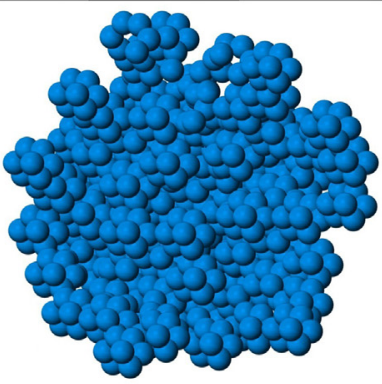

Pd nanodendrite

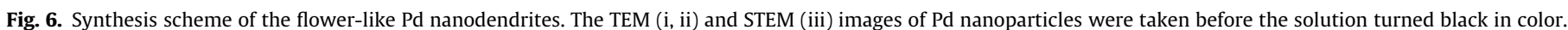
$c_{\mathrm{RNA}}=0.47 \mathrm{wt} \%, c_{\mathrm{AA}}=32 \mathrm{mM}$ and $c_{\mathrm{Pd}}=0.22 \mathrm{wt} \%$.
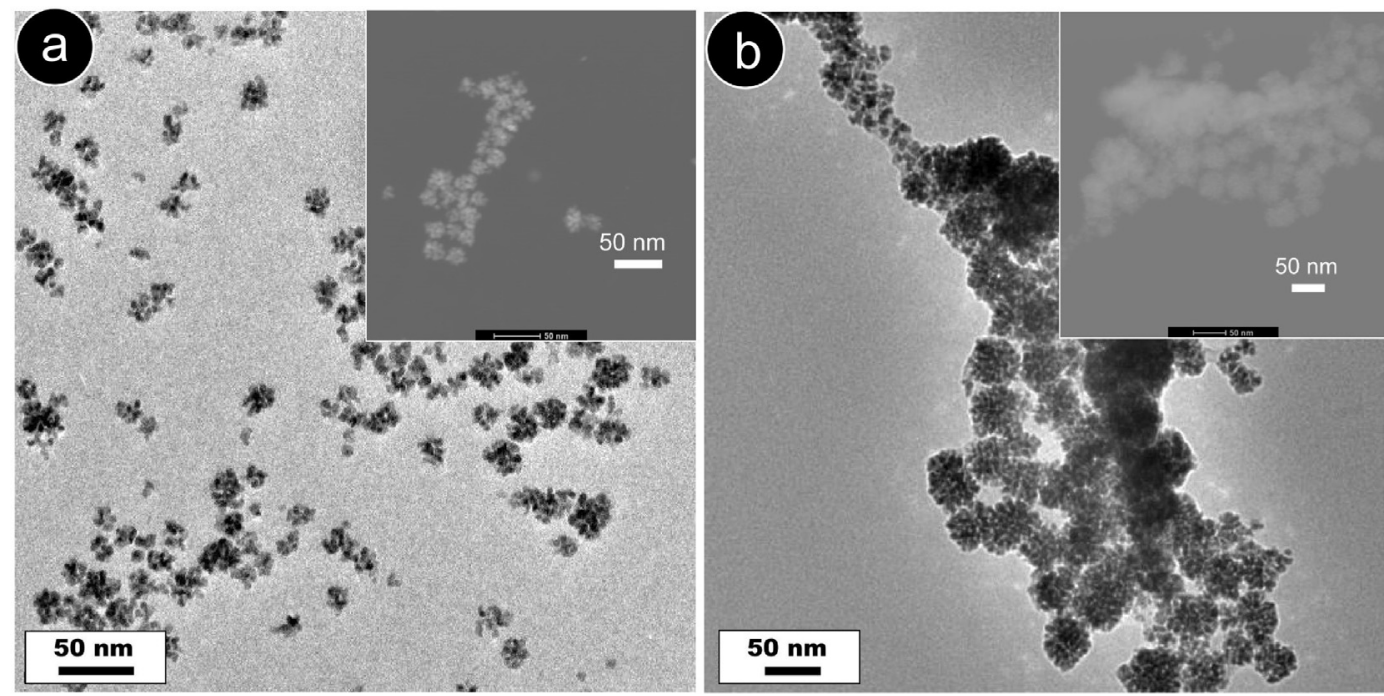

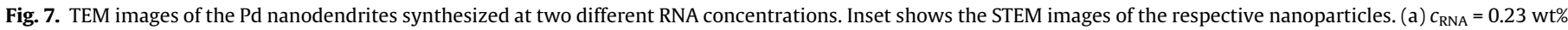
and (b) $c_{\mathrm{RNA}}=0.71 \mathrm{wt} \% . c_{\mathrm{AA}}=32 \mathrm{mM}$ and $c_{\mathrm{Pd}}=0.11 \mathrm{wt} \%$. 
crystalline rings related to $\left\{\begin{array}{lll}1 & 1 & 1\end{array}\right\},\left\{\begin{array}{lll}2 & 0 & 0\end{array}\right\},\left\{\begin{array}{lll}2 & 2 & 2\end{array}\right\}$ and $\left\{\begin{array}{llll}3 & 1 & 1\end{array}\right\}$ planes (Fig. 4(d)). The formation of such morphology can be ascribed to the capping role of ascorbic acid beside their main role in the Pd (II) reduction. The synthesis of Pd nanoparticles were also tried in the presence of only RNA, however, no Pd particle formation was observed. The TEM image of the reaction solution did not display any particles, but dark domains appeared due to the dispersions of RNA/Pd (Fig. 4(e)). Further, unlike other reaction systems catalyzed by ascorbic acid, the reaction mixture did not show color change to black even after $24 \mathrm{~h}$, demonstrating that RNA molecules could not reduce $\mathrm{Pd}^{2+}$ to $\mathrm{Pd}^{0}$ for the particle formation in the absence of ascorbic acid (Fig. S2).

Flower-like Pd nanodendrites were also synthesized at very low concentrations of RNA $(0.024$ and $0.048 \mathrm{wt} \%)$ to elucidate the underlying mechanism leading to the nanodendritic morphology. Fig. 5 shows the SEM and STEM images of the respective nanoparticles. Interestingly, when a low amount of RNA (0.024 wt\%) was used, firstly, the formation of less densely nanodendrites was observed within 2 mins, and with time, highly densely nanoparticles were formed, suggesting that more Pd atoms were bound to such structures and converted the overall morphology into densely nanodendrites (Fig. 5a-d). On the other hand, when the higher concentration of RNA $(0.048 \mathrm{wt} \%)$ was used, the formation of densely particles was observed even after $2 \mathrm{~min}$, suggesting the significance of RNA content on the morphology of the resultant particles: i.e., less densely Pd nanoparticles can be synthesized in the presence of low RNA content in short reaction times.
The formation mechanism of the nanodendritic morphology was explored by TEM analysis. Before the solution turned black in color, the sample taken from the solution showed small Pd particles sizing about $15 \mathrm{~nm}$, which were tending to form large nanoparticles through particle attachment (Fig. 6). With time, small nanoparticles disappeared, while larger nanoparticles were observed. After $3 \mathrm{~h}$, flower-like Pd nanoparticles were formed, demonstrating the formation of Pd nanodendrites through particle attachment. At room temperature, the growth of most Pd nanoparticles takes place slowly, and in this regard, stabilizing agents play a crucial role in the particle shape by changing the order of surface energies throughout the facets until the end-form has the lowest surface energy. However, the nanoparticles formed by kinetically-controlled synthesis mostly deviates from the thermodynamically favored structure, forming high index facets and concave surfaces. Due to high reaction temperature (i.e., $80^{\circ} \mathrm{C}$ ), the particle growth mainly proceeded in an uncontrolled way. The driving force for the particle growth is considered to be the reduction of the surface energy with particle attachment, ultimately forming nanodendrites with a polycrystalline structure [35].

The use of various synthesis routes has led to different flowerlike Pd nanoparticles. To the best of our knowledge, RNA-assisted synthesis route, for the first time, has been used to produce Pd nanodendrites whose size could readily be tuned by the RNA content used. In the particle synthesis, RNA acts as the capping agent and does not involve in the reduction of $\mathrm{Pd}^{2+}$ to $\mathrm{Pd}^{0}$. As a polyion, RNA binds to the facets of Pd nanoparticles without requiring
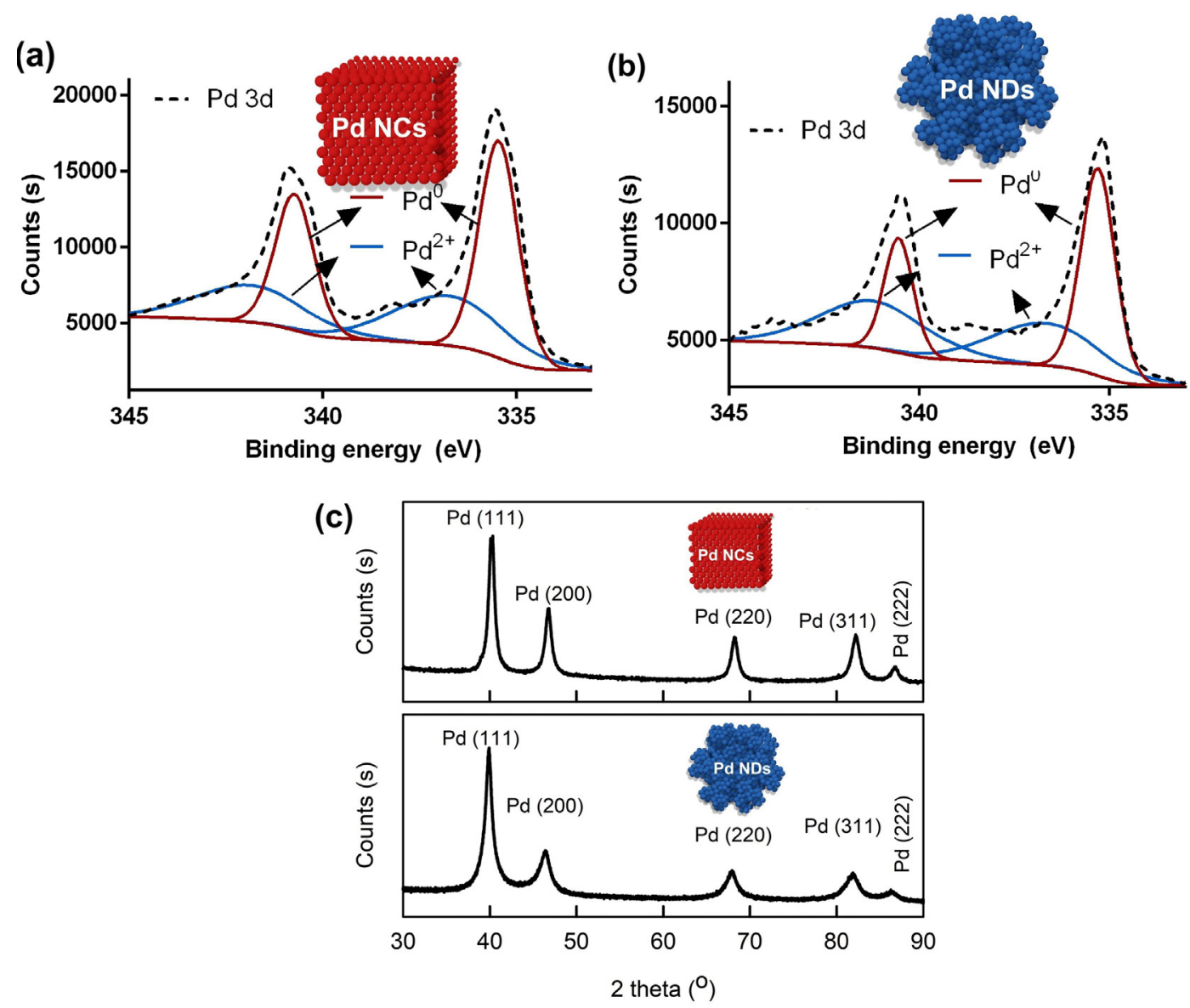

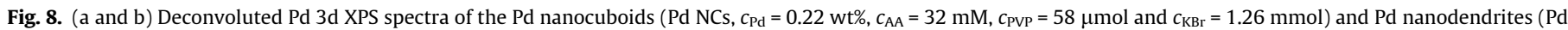

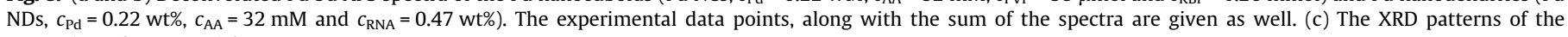
respective $\mathrm{Pd}$ nanoparticles. 
any other capping molecules, e.g., $\mathrm{KBr}$ and PVP, and its selfassembly property ultimately leads to nanodendritic morphology. Fig. 7 shows the TEM analysis of the Pd nanoparticles synthesized at two different RNA contents ( 0.23 and $0.71 \mathrm{wt} \%)$ in the presence of the same concentration of L-ascorbic acid and Pd. The TEM images of the respective nanoparticles showed that the particle size was also influenced by the RNA content when lower Pd content was used (i.e., $0.11 \mathrm{wt} \%$ ). The formation of larger Pd nanoparticles was evident, while the mean particle size significantly increased with an RNA content rise. This is a general trend for Pd nanoparticles and a similar increasing trend in the particle size was observed when the higher concentration of the capping agent was used [28]. This can be attributed to their tendency to form larger aggregates in the presence of higher RNA concentration.
With respect to the chemical state of Pd on the nanoparticle surface, XPS analysis was carried out to find the proportion of metallic and oxidized atoms. Fig. 8(a, b) shows the XPS spectra of Pd 3d electrons, where the sample showed a two-electronic transition because of the bands of $P d 3 d_{3 / 2}$ and Pd $3 d_{5 / 2}$, of which both were consisted of doublets [22]. The shift between these peaks is arisen due to the spin orbit coupling. The deconvoluted Pd 3d XPS spectra indicate $\operatorname{Pd}(0)$ is predominant in the particles. The occurrence of $\mathrm{Pd}(\mathrm{II})$ state on the particle surface can be attributed to the incomplete reduction of $\mathrm{Pd}^{2+}$ to $\mathrm{Pd}^{0}$. The relative percentage of $\mathrm{Pd}^{2+}$ and $\mathrm{Pd}^{0}$ atoms was respectively found as 30 and $70 \%$ with the corresponding $\mathrm{Pd}^{2+} / \mathrm{Pd}^{0}$ of 0.43 . Fig. $8 \mathrm{c}$ shows the XRD patterns of Pd NCs and NDs revealed the presence of $\left\{\begin{array}{lll}1 & 1 & 1\end{array}\right\},\left\{\begin{array}{lll}2 & 0 & 0\end{array}\right\},\left\{\begin{array}{lll}2 & 2 & 0\end{array}\right\}$, $\left\{\begin{array}{lll}3 & 1 & 1\end{array}\right\}$ and $\left\{\begin{array}{lll}2 & 2 & 2\end{array}\right\}$ crystal planes, demonstrating the
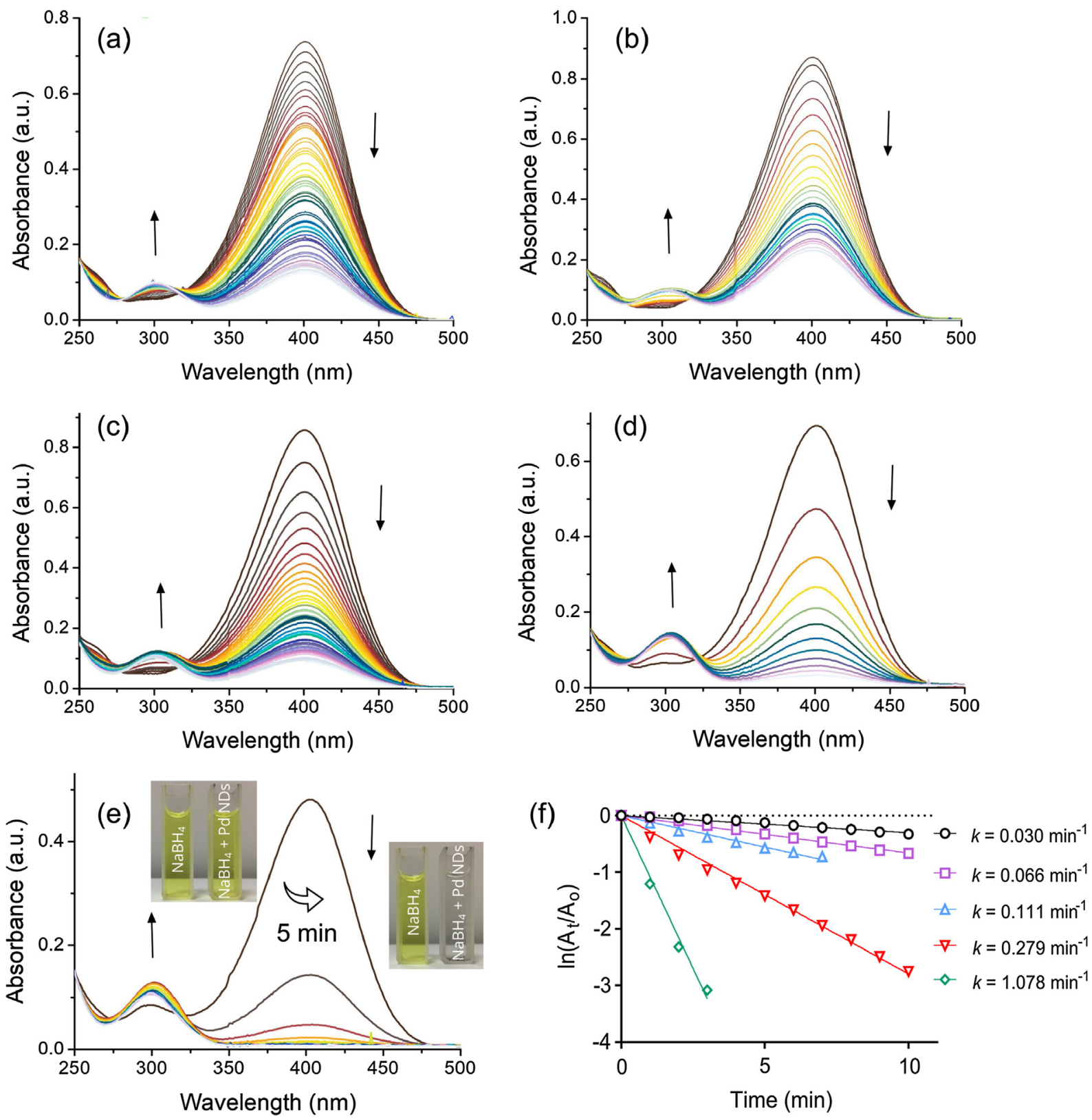

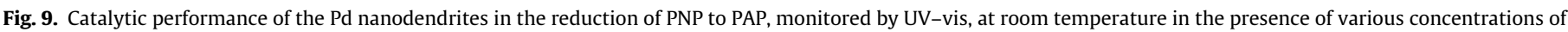

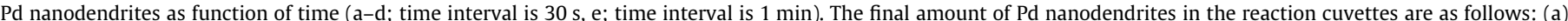

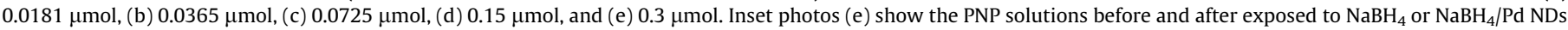
for 5 min. (f) The kinetic rate of PNP reduction with respect to time. 
polycrystalline structure of both nanoparticles. This is in line with the SAED patterns of the respective nanoparticles (Fig. 3c, inset). The corresponding $d$-spacing values were respectively calculated as $2.236,1.936,1.369,1.170$ and $1.116 \AA$, demonstrating the presence of metallic Pd with a fcc structure. The highest peak intensity was observed for $\left\{\begin{array}{lll}1 & 1 & 1\end{array}\right\}$ plane, followed by $\left\{\begin{array}{lll}2 & 0 & 0\end{array}\right\}$. The $\left\{\begin{array}{lll}1 & 1 & 1\end{array}\right\}$ plane is the most active facet among low index planes. Furthermore, the cuboid nanoparticles are likely larger in a single crystal domain size than the nanodendritic nanoparticles due to the presence of narrower peak widths in the XRD patterns.

Polycrystalline structure can be attributed to the uncontrolled growth of Pd nanoparticles. The firstly formed small particles coalesced into seeds, followed by the attachment of the remaining particles to reduce surface energy. The process continued until flower-like nanodendrites were formed as shown in Fig. 3, where the average crystalline sizes regarding $\left\{\begin{array}{lll}1 & 1 & 1\end{array}\right\}$ and $\left\{\begin{array}{lll}2 & 0 & 0\end{array}\right\}$ reflections were dominant due to their anisotropy. This also shows the preferential orientation of $\left\{\begin{array}{lll}1 & 1 & 1\end{array}\right\}$ and $\left\{\begin{array}{lll}2 & 0 & 0\end{array}\right\}$ facets.

The catalytic activity of the Pd nanodendrites was explored over the reduction of nitroaromatic compounds. Nitroaromatic compounds are mostly synthetic molecules and rarely found in nature. They are hazardous to human health and thus, registered as the priority pollutants for environmental remediation on the U.S. Environmental Agency's list [36]. They have been used for the synthesis of polymers, pesticides and explosives [36]. In this study, we used Pd nanodendrites for the reduction of $p$-nitrophenol (PNP) and 2,4,6-trinitrotoluene (TNT) to p-aminophenol (PAP) and 2,4,6triaminotoluene (TAT) as a function of time in the presence of $\mathrm{NaBH}_{4}$ as a co-catalyst. Pd nanoparticles decorated nanowebs were previously used in the reduction of PNP [37] and TNT [38]. Nitro groups can easily be reduced to give amino compounds by the help of metals in the presence of $\mathrm{H}^{+}$. Normally, PNP solution gives an absorbance peak at $316 \mathrm{~nm}$, and after the addition of $\mathrm{NaBH}_{4}$, it shifted to $400 \mathrm{~nm}$, and with that, the solution became yellowish owing to the formation of $p$-nitrophenolate ion. In the absence of
Pd nanodendrites, the reduction rate was extremely slow. Upon the addition of small amount of Pd nanodendrites (i.e., $0.0181 \mu \mathrm{mol})$, the absorption peak at $400 \mathrm{~nm}$ decreased and a new peak appeared at $300 \mathrm{~nm}$, which was ascribed to the formation of $p$-aminophenol (PAP). An inverse correlation between two peaks depending on the nanoparticle content was shown in Fig. 9a-e, suggesting the reduction reaction proceeds slowly in the presence of low amount of the catalyst and faster at higher catalyst contents. The $\mathrm{NaBH}_{4}$ content in the system is excessive to be ensure that the reaction follows pseudo-first-order kinetics with respect to PNP only: hence, the reaction kinetics can be formulated as $-k t=\ln \left(A_{\mathrm{t}} / A_{0}\right)$, in which $\mathrm{k}$ is the first-order rate constant, $t$ is the reaction time while $A_{\mathrm{t}}$ and $A_{0}$ stand for the absorbance at time $t$ and 0 , respectively. The linear relationship of $k t=\ln \left(A_{\mathrm{t}} / A_{0}\right)$ versus reaction time for the systems containing various catalyst loadings was shown in Fig. 9f. The rate constant $(k)$ was determined from the slope of the fitted lines. Higher catalyst content increased the reaction rate $(k)$, and the reaction was completed in few minutes. The representative optical photos of the PNP solution before and after the nanoparticle treatment shows that the yellowish solution becomes colorless, suggesting the conversion of PNP to PAP by the naked eye (Fig. 9e). The highest $k$ was calculated as $1.078 \mathrm{~min}^{-1}\left(17.9 \times 10^{-3} \mathrm{~s}^{-1}\right)$. Since the used Pd nanodendrite (Pd ND) content is $0.3 \times 10^{-3} \mathrm{mmol}$, the normalized rate constant $\left(k_{\text {nor }}\right)$ of the reaction is calculated to be $59.66 \mathrm{mmol}^{-1} \mathrm{~s}^{-1}$. This high catalytic activity of the Pd nanodendrites can be attributed to their highly branched morphology. The respective TOF value was calculated as $16.06 \mathrm{~h}^{-1}$.

Likewise, flower-like Pd nanodendrites were also exploited in the reduction of 2,4,6-trinitrotoluene (TNT) in water. The reaction was performed at room temperature using various concentrations of Pd nanodendrites. The time-dependent UV-Vis spectra during the reduction of TNT in the presence of various catalyst contents were shown in Fig. 10. After the addition of $\mathrm{NaBH}_{4}$, a clear peak appears at $420 \mathrm{~nm}$ in the UV-Vis spectrum of the TNT. With the
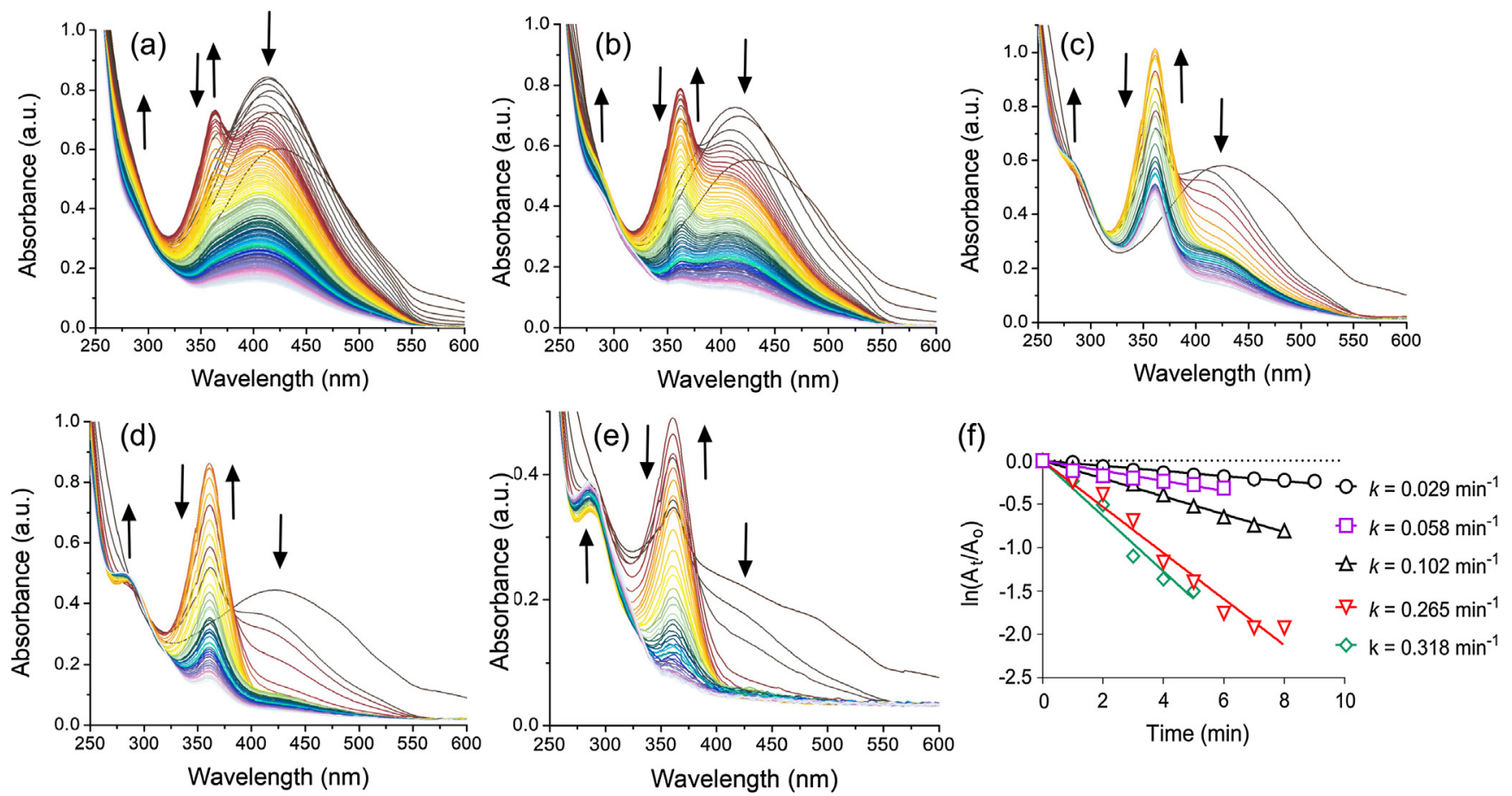

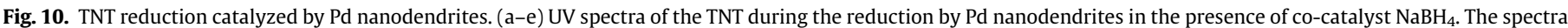

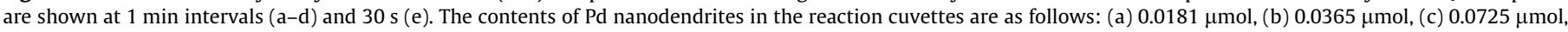
(d) $0.15 \mu \mathrm{mol}$, and (e) $0.3 \mu \mathrm{mol}$. (f) The kinetic rate of the TNT reduction with respect to time. 
reduction of nitro groups, a new peak appeared at $350 \mathrm{~nm}$, suggesting the reduction of nitro groups to amine. Increasing the concentration of Pd nanodendrites significantly increased the reaction rate (Fig. 10f). The reaction rate constant $(k)$ varied between 0.029 and $0.32 \mathrm{~min}^{-1}$ depending on the nanodendrite content used, and the highest $k$ was calculated as $0.32 \mathrm{~min}^{-1}$ $\left(5.30 \times 10^{-3} \mathrm{~s}^{-1}\right)$. Since the used Pd NDs content is $0.3 \times 10^{-3}$ $\mathrm{mmol}$, the normalized rate constant $\left(k_{\text {nor }}\right)$ of the reaction is calculated to be $17.66 \mathrm{mmol}^{-1} \mathrm{~s}^{-1}$ for TNT. The corresponding TOF value for the reduction of TNT molecules was calculated as $40.80 \mathrm{~h}^{-1}$.

\section{Conclusion}

A facile and green synthesis route of flower-like Pd nanodendrites was reported. Using RNA as the capping agent led to flower like morphology via aggregation-based nanoparticle growth, while the formation of cuboid nanoparticles was observed in the presence of $\mathrm{KBr} / \mathrm{PVP}$. The nanodendritic morphology was attributed to the RNA-assisted aggregation of small particles, which was confirmed by TEM at the onset of the nanoparticle formation. Increasing RNA content led to larger nanodendrites. The oxidation state of Pd was explored by XPS as $\mathrm{Pd}^{2+} \mathrm{Pd}^{0}$ of 0.43 . The occurrence of highly branched morphology was analyzed by HRTEM analysis, which revealed the presence of various crystalline planes. Their polycrystalline structure was also confirmed by SAED and XRD analysis. The catalytic activity of the nanodendrites was tested over the reduction of PNP and TNT to PAP and TAT: reduction rate constants $(k)$ were found as $1.078 \mathrm{~min}^{-1}\left(k_{\mathrm{nor}}=59.66 \mathrm{mmol}^{-1} \mathrm{~s}^{-1}\right)$ for PNP and $0.3181 \mathrm{~min}^{-1}\left(k_{\text {nor }}=17.6 \mathrm{mmol}^{-1} \mathrm{~s}^{-1}\right)$ for TNT and the corresponding TOF values were calculated as 16.06 and $40.80 \mathrm{~h}^{-1}$, respectively. The high catalytic activity of Pd nanodendrites can be ascribed to their highly branched nanodendritic morphology. Due to their facile green synthesis and tunable particle size, Pd nanodendrites are promising catalytic nanomaterials for the reduction of nitroaromatic compounds.

\section{Conflict of interest}

The authors declare no competing financial interest.

\section{Appendix A. Supplementary material}

The following files are available free of charge. TEM, STEM images, and the optical photos of Pd dispersions. This material is available free of charge via the Internet at http://pubs.acs.org. Supplementary data to this article can be found online at https://doi org/10.1016/j.jcis.2019.02.083.

\section{References}

[1] X. Wang, A. Ruditskiy, Y. Xia, Rational design and synthesis of noble-meta nanoframes for catalytic and photonic applications, Natl. Sci. Rev. 3 (4) (2016) 520-533.

[2] S.A.N.K. Eugenii, W. Itamar, Nanoparticle arrays on surfaces for electronic optical, and sensor applications, Chemphyschem 1 (1) (2000) 18-52.

[3] G. Doria, J. Conde, B. Veigas, L. Giestas, C. Almeida, M. Assunção, J. Rosa, P.V Baptista, Noble metal nanoparticles for biosensing applications, Sensors (Basel, Switzerland) 12 (2) (2012) 1657-1687.

[4] R.R. Arvizo, S. Bhattacharyya, R. Kudgus, K. Giri, R. Bhattacharya, P. Mukherjee, Intrinsic therapeutic applications of noble metal nanoparticles: past, present and future, Chem. Soc. Rev. 41 (7) (2012) 2943-2970.

[5] G. Paramasivam, N. Kayambu, A.M. Rabel, A.K. Sundramoorthy, A. Sundaramurthy, Anisotropic noble metal nanoparticles: synthesis, surface functionalization and applications in biosensing, bioimaging, drug delivery and theranostics, Acta Biomater. 49 (2017) 45-65.

[6] E.D. Goodman, S. Dai, A.-C. Yang, C.J. Wrasman, A. Gallo, S.R. Bare, A.S. Hoffman, T.F. Jaramillo, G.W. Graham, X. Pan, M. Cargnello, Uniform Pt/Pd bimetallic nanocrystals demonstrate platinum effect on palladium methane combustion activity and stability, ACS Catal. 7 (7) (2017) 4372-4380.
[7] S.J. Mejía-Rosales, C. Fernández-Navarro, E. Pérez-Tijerina, D.A. Blom, L.F. Allard, M. José-Yacamán, On the structure of Au/Pd bimetallic nanoparticles, J. Phys. Chem. C 111 (3) (2007) 1256-1260.

[8] P. Verma, Y. Kuwahara, K. Mori, H. Yamashita, Synthesis and characterization of a Pd/Ag bimetallic nanocatalyst on SBA-15 mesoporous silica as a plasmonic catalyst, J. Mater. Chem. A 3 (37) (2015) 18889-18897.

[9] M. Ashok, G. Niti, J. Rongchao, A universal approach to the synthesis of noble metal nanodendrites and their catalytic properties, Angew. Chem. Int. Ed. 49 29) (2010) 4962-4966.

[10] Y.-H. Chen, H.-H. Hung, M.H. Huang, Seed-mediated synthesis of palladium nanorods and branched nanocrystals and their use as recyclable suzuki coupling reaction catalysts, J. Am. Chem. Soc. 131 (25) (2009) 9114-9121.

[11] G. Su, H. Jiang, H. Zhu, J.-J. Lv, G. Yang, B. Yan, J.-J. Zhu, Controlled deposition of palladium nanodendrites on the tips of gold nanorods and their enhanced catalytic activity, Nanoscale 9 (34) (2017) 12494-12502.

[12] J. Ge, W. Xing, X. Xue, C. Liu, T. Lu, J. Liao, Controllable synthesis of Pd nanocatalysts for Direct Formic Acid Fuel Cell (DFAFC) application: from Pd hollow nanospheres to Pd nanoparticles, J. Phys. Chem. C 111 (46) (2007) $17305-17310$

[13] Q. Gao, M.-R. Gao, J.-W. Liu, M.-Y. Chen, C.-H. Cui, H.-H. Li, S.-H. Yu, One-pot synthesis of branched palladium nanodendrites with superior electrocatalytic performance, Nanoscale 5 (8) (2013) 3202-3207.

[14] X.-F. Zhang, Y. Chen, L. Zhang, A.-J. Wang, L.-J. Wu, Z.-G. Wang, J.-J. Feng, Polyl-lysine mediated synthesis of palladium nanochain networks and nanodendrites as highly efficient electrocatalysts for formic acid oxidation and hydrogen evolution, J. Colloid Interface Sci. 516 (2018) 325-331.

[15] R.K. Pandey, S. Patnaik, V. Lakshminarayanan, Thin film of palladium nanodendrites supported on graphite electrode for catalyzing the oxidation of small organic molecules, Catal. Lett. 144 (6) (2014) 965-970.

[16] Y.W. Lee, M. Kim, Y. Kim, S.W. Kang, J.-H. Lee, S.W. Han, Synthesis and electrocatalytic activity of Au-Pd alloy nanodendrites for ethanol oxidation, J. Phys. Chem. C 114 (17) (2010) 7689-7693.

[17] R. Chang, L. Zheng, C. Wang, D. Yang, G. Zhang, S. Sun, Synthesis of hierarchical platinum-palladium-copper nanodendrites for efficient methanol oxidation, Appl. Catal. B: Environ. 211 (2017) 205-211.

[18] S. Kidambi, J. Dai, J. Li, M.L. Bruening, Selective hydrogenation by Pd nanoparticles embedded in polyelectrolyte multilayers, J. Am. Chem. Soc. 126 (9) (2004) 2658-2659.

[19] C. Hao, H. Yulian, P.L.D.P. Weihua, W. Yulong, Q. Suitao, Phenol catalytic hydrogenation over palladium nanoparticles supported on metal-organic frameworks in the aqueous phase, ChemCatChem 10 (12) (2018) 2558 2570.

[20] J. García-Calvo, P. Calvo-Gredilla, S. Vallejos, J.M. García, J.V. Cuevas-Vicario, G. García-Herbosa, M. Avella, T. Torroba, Palladium nanodendrites uniformly deposited on the surface of polymers as an efficient and recyclable catalyst for direct drug modification via Z-selective semihydrogenation of alkynes, Green Chem. 20 (16) (2018) 3875-3883.

[21] N. Arjona, M. Guerra-Balcazar, F.M. Cuevas-Muniz, L. Alvarez-Contreras, J. Ledesma-Garcia, L.G. Arriaga, Electrochemical synthesis of flower-like Pd nanoparticles with high tolerance toward formic acid electrooxidation, RSC Adv. 3 (36) (2013) 15727-15733.

[22] M. Navlani-García, P. Verma, K. Mori, Y. Kuwahara, H. Yamashita, Morphologycontrolled Pd nanocrystals as catalysts in tandem dehydrogenationhydrogenation reactions, J. Chem. Sci. 129 (11) (2017) 1695-1703.

[23] Y. Piao, Y. Jang, M. Shokouhimehr, S. Lee In, T. Hyeon, Facile aqueous-phase synthesis of uniform palladium nanoparticles of various shapes and sizes, Small 3 (2) (2007) 255-260.

[24] W. Pan, X. Zhang, H. Ma, J. Zhang, Electrochemical synthesis, voltammetric behavior, and electrocatalytic activity of Pd nanoparticles, J. Phys. Chem. C 112 (7) (2008) 2456-2461.

[25] H. Zhang, M. Jin, Y. Xiong, B. Lim, Y. Xia, Shape-controlled synthesis of Pd nanocrystals and their catalytic applications, Acc. Chem. Res. 46 (8) (2013) 1783-1794.

[26] X. Xie, G. Gao, Z. Pan, T. Wang, X. Meng, L. Cai, Large-scale synthesis of palladium concave nanocubes with high-index facets for sustainable enhanced catalytic performance, Sci. Rep. 5 (2015) 8515.

[27] M.S. Bakshi, 1D flower-like morphologies of palladium nanoparticles using strongly hydrophobic surfactants, J. Phys. Chem. C 113 (25) (2009) 10921 10928.

[28] S.J. Ye, D.Y. Kim, S.W. Kang, K.W. Choi, S.W. Han, O.O. Park, Synthesis of chestnut-bur-like palladium nanostructures and their enhanced electrocatalytic activities for ethanol oxidation, Nanoscale 6 (8) (2014) 4182-4187.

[29] D.H. Shin, J.S. Lee, J. Jun, J.H. An, S.G. Kim, K.H. Cho, J. Jang, Flower-like palladium nanoclusters decorated graphene electrodes for ultrasensitive and flexible hydrogen gas sensing, Sci. Rep. 5 (2015) 12294.

[30] Y. Liu, D.-D. Wang, L. Zhao, M. Lin, H.-Z. Sun, H.-C. Sun, B. Yang, Polypyrrolecoated flower-like Pd nanoparticles (Pd NPs@PPy) with enhanced stability and heat conversion efficiency for cancer photothermal therapy, RSC Adv. 6 (19) (2016) 15854-15860

[31] H. Wang, B. Zeng, Y. Zhao, M. Li, H. Liu, T. Huang, Controlled synthesis of hierarchical Pd nanodendrites and their electrocatalytic properties, J. Nanosci. Nanotechnol. 18 (1) (2018) 730-734.

[32] N. Ortiz, S.E. Skrabalak, Manipulating local ligand environments for the controlled nucleation of metal nanoparticles and their assembly into nanodendrites, Angew. Chem. Int. Ed. 51 (47) (2012) 11757-11761. 
[33] L.A. Gugliotti, D.L. Feldheim, B.E. Eaton, RNA-mediated control of metal nanoparticle shape, J. Am. Chem. Soc. 127 (50) (2005) 17814-17818.

[34] C. Li, M. Imura, Y. Yamauchi, A universal approach to the preparation of colloidal mesoporous platinum nanoparticles with controlled particle sizes in a wide range from $20 \mathrm{~nm}$ to $200 \mathrm{~nm}$, Phys. Chem. Chem. Phys 16 (2014) 87878790.

[35] J.F. Banfield, S.A. Welch, H. Zhang, T.T. Ebert, R.L. Penn, Aggregation-based crystal growth and microstructure development in natural iron oxyhydroxide biomineralization products, Science 289 (5480) (2000) 751-754.
[36] K.-S. Ju, R.E. Parales, Nitroaromatic compounds, from synthesis to biodegradation, Microbiol. Mol. Biol. Rev. 74 (2) (2010) 250-272.

[37] K.S. Ranjith, A. Celebioglu, H. Eren, N. Biyikli, T. Uyar, Monodispersed, highly interactive facet (111)-oriented Pd nanograins by ALD onto free-standing and flexible electrospun polymeric nanofibrous webs for catalytic application, Adv Mater. Interf. 4 (24) (2017) 1700640.

[38] O. Arslan, H. Eren, N. Biyikli, T. Uyar, Reusable and flexible heterogeneous catalyst for reduction of TNT by Pd nanocube decorated $\mathrm{ZnO}$ nanolayers onto electrospun polymeric nanofibers, ChemistrySelect 2 (28) (2017) 8790-8798. 